\title{
INCREASING IMAGINATION CREATIVITY STUDENTS' OF INDONESIAN LANGAUGE LEARNING THROUGH CLOZE DILITION TECHNIQUE (TCD) IN POETRY AT SIXTH GRADE STUDENTS' IN SD NEGERI NO. 27 SUNGAI TAWAR KECAMATAN KOTO XI TARUSAN
}

\section{ETI}

Volume 2 Nomor 1

JIPS ISSN: 2579-5449

\begin{abstract}
Poetry is a literary material in the elementary school. Because poetry is a literary work that is forgotten spontaneously by using imagination as a guide of the mind, then in the presentation of poetry on the students should use a proper way or technique so that students can imagine as done by the author with a strong imagination to poetry.

Through Indonesian Learning to Use Technique Cloze Dilition (TCD) in Poetry To Enhance Creativity Learning Imagination Indonesian Lesson In Grade VI SD Negeri No. 27 Fresh River District of Koto XI Tarusan.

Research methods that the authors use to achieve the above objectives is a classroom action research Through Learning Indonesian to Increase creativity imanjination. This study is done in sixth grade students at SD Negeri No. 07 Sungai Tawar Kecamatan Koto XI Tarusan

Based on the results of the analysis can be concluded that Through Learning Indonesian language showed improving starting from the results of formative tests. This means that Through Learning Indonesian language managed to improve creativity of students' imangination.
\end{abstract}

Keywords: imagination creativity, Indonesian language, cloze dilition technique (TCD), poetry

MENINGKATKAN KREATIFITAS IMANJINASI PADA MATA
PELAJARAN BAHASA INDONESIA MELALUI PENGGUNAAN
TECHNIQUE CLOZE DILITION ( TCD ) DALAM PEMBELAJARAN
PUISI UNTUK SISWA KELAS VI SD NEGERI NO.07 SUNGAI TAWAR
KECAMATAN KOTO XI TARUSAN

\begin{abstract}
ABSTRAK
Puisi merupakan materi sastra yang ada di SD. Karena puisi merupakan suatu karya sastra yang dilupakan secara sepontan dengan mempergunakan imajinasi sebagai pembantu akal pikiran, maka dalam penyajian puisi pada siswa hendaknya menggunakan suatu cara atau

tehnik yang tepat agar siswa dapat berimajinasi seperti yang dilakukan oleh pengarang. Dengan daya imajinasi yang kuat terhadap puisi.

Melalui Pembelajaran bahasa indonesia untuk Penggunaan Technique Cloze Dilition (TCD) Dalam Pembelajaran Puisi Untuk
\end{abstract}


Meningkatkan Kreatifitas Imanjinasi Pada Mata Pelajaran Bahasa Indonesia Siswa Kelas VI SD Negeri No.07 Sungai Tawar Kecamatan Koto XI Tarusan. Metode penelitian yang penulis gunakan untuk mencapai tujuan di atas adalah penelitian tindakan kelas Melalui Pembelajaran bahasa indonesia untuk Meningkatkan kreatifitas imanjinasi. Pelaksnaan penelitian ini di kelas VI
SD Negeri No.07 Sungai Tawar Kecamatan Koto XI Tarusan

Berdasarkan hasil analisis dapat disimpulkan bahwa Melalui Pembelajaran bahasa indonesia menunjukan peningktan mulai dari hasil tes formatif. Hal tersebut berarti Melalui Pembelajaran bahasa indonesia berhasil meningkatkan kreatifitas imanjinasi siswa.

\section{Kata kunci: imajinasi, bahasa indonesia, teknik cloze dilition, puisi}

\section{PENDAHULUAN}

Latar Belakang Masalah Bahasa Indonesia merupakan mata pelajaran yang diberikan pada semua jenjang pendidikan formal, baik di tingkat pendidikan dasar atau menengah. Berbicara Bahasa Indonesia sebagai mata pelajaran wajib yang ada di sekitar jenjang pendidikan, maka kita perlu memahami tentang hakikat pembelajaran bahasa, yaitu belajar bahasa adalah belajar berkomunikasi dan belajar sastra adalah belajar menghargai manusia dan nilai-nilai kemanusiaannya. Oleh karena itu, pembelajaran Bahasa Indonesia mengupayakan peningkatan kemampuan siswa untuk berkomunikasi secara lisan dan tertulis serta menghargai karya cipta bangsa Indonesia.

Di dalam Puskur (2002) dinyatakan bahwa secara umum tujuan pengajaran bahasa dan sastra Indonesia adalah (1) siswa menghargai dan membanggakan bahasa dan sastra Indonesia sebagai bahasa persatuan (nasional) dan bahasa negara; (2) Siswa memahami bahasa Indonesian dari segi bentuk, makna dan fungsi serta menggunakannya dengan tepat dan kreatif untuk bermacam-macam tujuan, keperluan dan keadaan; (3) Sisa memiliki kemampuan menggunakan emosianal dan kematangan sosial; (4) Memiliki disiplin dalam berfikir dalam berbahasa (berbicara dan menulis); (5) Siswa mampu menikmati dan memanfaatkan karya sastra untuk mengembangkan kepribadian, memperluas wawasan kehidupan, serta meningkatkan pengetahuan dan kemampuan berbahasa wawasan kehidupan serta meningkatkan pengetahuan dan kemampuan berbahasa; dan (6) Siswa menghargai dan membanggakan sastra Indonesia sebagai khasanah budaya dan intelektual manusia Indonesia.
Selanjutnya dengan tujuan umum tersebut, maka kita harus mengetahui kompetensi yang harus dimiliki oleh siswa sekolah dasar terutama dalam pembelajaran apresiasi sastra. Kompetensi tersebut adalah mengapresiasikan serta melalui kegiatan mendengarkan, menonton, membaca dan melisankan hasil sastra berupa dongeng puisi, drama serta menuliskan pengalaman dalam bentuk cerita dan puisi. Sedangkan materi sastra yang dipelajari siswa SD dapat berupa cerita, drama (dialog) dan puisi.

Puisi merupakan materi sastra yang ada di SD. Karena puisi merupakan suatu karya sastra yang dilupakan secara sepontan dengan mempergunakan imajinasi sebagai pembantu akal pikiran, maka dalam penyajian puisi pada siswa hendaknya menggunakan suatu cara atau tehnik yang tepat agar siswa dapat berimajinasi seperti yang dilakukan oleh pengarang. Dengan daya imajinasi yang kuat terhadap puisi.

Salah satu tehnik atau cara yang dapat meningkatkan daya imajinasi siswa terhadap puisi adalah degan menggunakan tehnik cloze (dilition) atu kelesapan, artinya menghilangkan atu melepaskan sebuah (atau lebih) kata pada larik /baris puisi.

Dengan memperhatikan latar belakang di atas, peneliti berkeyakinan bahwa dengan kemampuan siswa berimajinasi terhadap puisi dapat meningkatkan kemampuan siswa dalam pengekspresian terhadap karya sastra (khususnya puisi ) yang pada akhirnya dapat menhargai kesastraan bangsa sendiri. Kemampuan siswa dalam berimajinasi dapat berpengaruh terhadap prestasi siswa. Oleh karena itu guru memegang peranan yang sangat penting dalam pembelajaran di kelas. Agar proses pembelajaran khususnya dalam penyajian puisi di kelas dapat mencapai 
hasil yang maksimal,maka guru harus dapat menentukan cara atau tehnik penyajian materi yang tepat khusunya dalam penyajian puisi. Cara atau tehnik penyajian puisi yang tepat adalah dengan menggunakan tehnik "Cloze" (dilition ) atau kelesapan dengan menggunakan tehnik cloze ini, dapat mendorong siswa mengalami proses berimajinasi terhadap puisi seperti yang dilakukan oleh pengarang.

Berdasarkan kenyatan tersebut diatas, penulis mengadakan penelitian tentang: Pengunaan Tehnik Cloze (Dilition) Pada Pembelajaran Puisi Mata Pelajaran Bahasa Indanesia Untuk Meningkatkan Kreatifitas Berfikir Siswa Kelas VI SD Negeri No.07 Sungai Tawar Kecamatan Koto XI Tarusan.

Perumusan Masalah PTK, 1) Bagaimanakah aktifitas belajar siswa Kelas VI SD Negeri No.07 Sungai Tawar Kecamatan Koto XI Tarusan selama mengikuti pembelajaran penyusunan puisi dengan menggunakan tehnik cloze? 2) Bagaimanakah kreatifitas berfikir siswa Kelas VI SD Negeri No.07 Sungai Tawar Kecamatan Koto XI Tarusan terhadap puisi dengan menggunakan tehnik cloze? 3) Bagaimanakah prestasi belajar siswa Kelas VI SD Negeri No.07 Sungai Tawar Kecamatan Koto XI Tarusan setelah mengikuti pembelajaran puisi dengan menggunakan tehnik cloze? 4) Apakah hambatan yang ditemui selama pembelajaran dengan menggunakan tehnik cloze ?

Tujuan Penelitian Tindakan 1) Untuk mendiskripkan aktifitas belajar siswa Kelas VI
SD Negeri No.07 Sungai Tawar Kecamatan Koto XI Tarusan selama mengikuti pembelajaran dengan menggunakan tehnik cloze? 2) Untuk mendiskripsikan kreatifitas berfikir siswa Kelas VI SD Negeri No.07 Sungai Tawar Kecamatan Koto XI Tarusan terhadap puisi dengan menggunakan tehnik cloze. 3) Untuk mendiskripsikan prestasi belajar siswa Kelas VI SD Negeri No.07 Sungai Tawar Kecamatan Koto XI Tarusan setelah mengikuti pembelajaran puisi dengan menggunakan tehnik cloze. 4) Untuk mendiskripsikan hambatan yang ditemui selama pembelajaran dengan menggunakan tehnik cloze.

Hipotesis penelitian ini adalah : 1) Ada pengaruh penggunaan tehnik cloze dalam pembelajaran puisi terhadap aktivitas belajar siswa Kelas VI SD Negeri No.07 Sungai Tawar Kecamatan Koto XI Tarusan. 2) Ada pengaruh penggunaan tehnik cloze dalam pembelajaran puisi terhadap kreatifitas berfikir siswa Kelas VI SD Negeri No.07 Sungai Tawar Kecamatan Koto XI Tarusan. 3) Ada pengaruh penggunaan tehnik cloze dalam pembelajaran puisi terhadap hasil belajar siswa Kelas VI SD Negeri No.07 Sungai Tawar Kecamatan Koto XI Tarusan. 4) Ada hambatan yang ditemui siswa penggunaan tehnik cloze dalam pembelajaran puisi. 


\section{METODE PENELITIAN}

Penelitian yang penulis lakukan ini adalah penelitian tindakan kelas (PTK) yang bertujuan untuk memperbaiki proses pembelajaran yang ada dikelas. Oleh karena itu sebelum dilaksanakan kegiatan penelitian perlu disusun suatu rancangan penelitian.
Dalam penelitian itu penulis merancang tiga siklus yang masing-masing siklus mengalami empat tahapan, yaitu : 1 . Perencanaan, 2. Pelaksanaan, 3. Pengamatan, 4. Refleksi. Adapun modelnya adalah sebagai berikut :

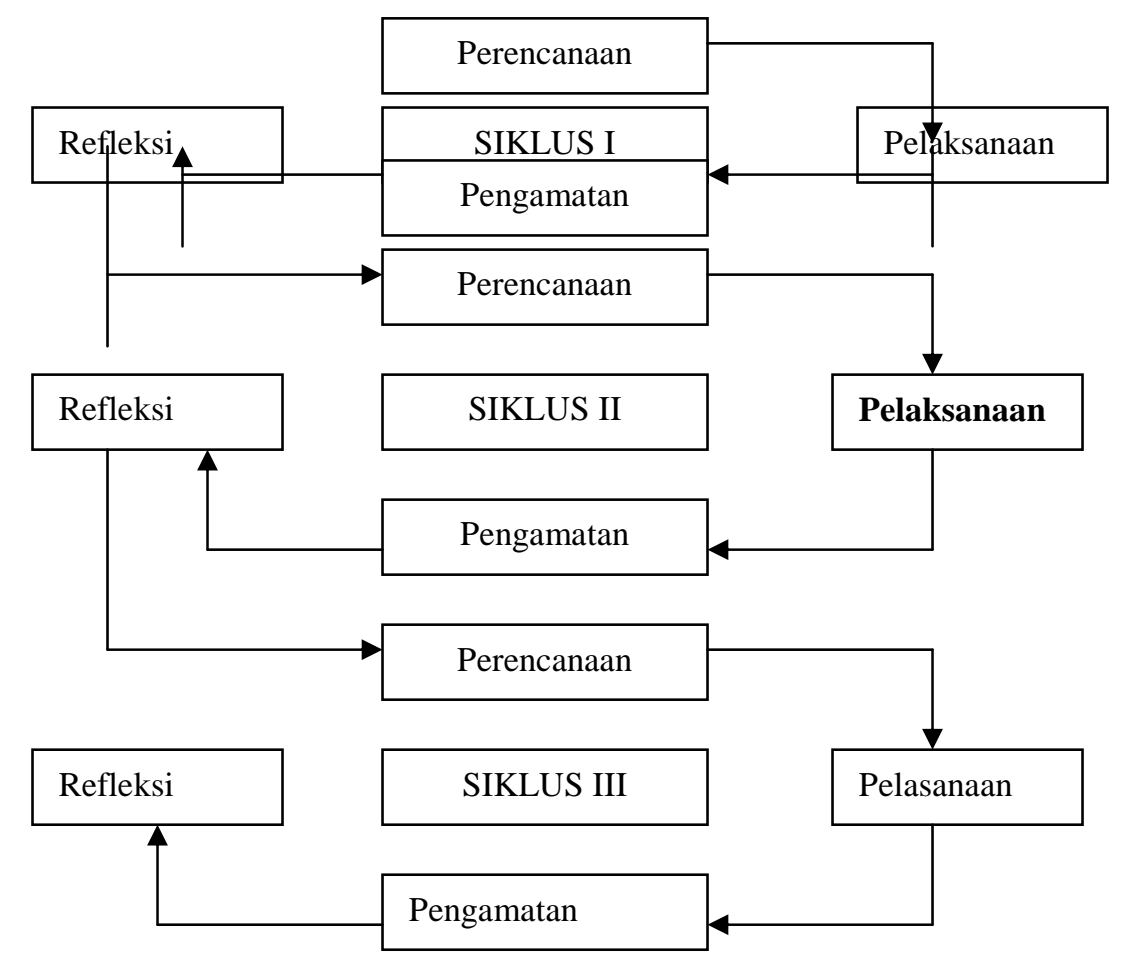

\section{SIKLUS I}

1. Perencanaan

Pada tahap penelitian menentukan langkah-langkah sebagai berikut :

a) Mempersiapkan rencana pembelajaran

b) Mempersiapkan teks puisi yang telah dilepaskan

c) Guru bersama siswa membahas proses pembelajaran yang akan dilaksanakan meliputi :

- Siswa menerima puisi yang telah dilepaskan

- Siswa melemgkapi puisi yang telah dilepaskan

- Siswa menukarkan hasil kerjannya kepada teman lain

- Guru membacakan / memperdengarkan puisi aslinya

- Kegiatan apresiasi

d) Guru membuat format pengamatan

2. Pelaksanaan
Dalam tahap pelaksanaan ini langkah-langkah yang ditempuh adalah sebagai berikut :

a) Persiapan guru meliputi :

- Menyiapkan teks puisi yang telah dilepaskan

- Menyiapkan teks puisi aslinya

- Menyiapkan format pengamatan

b) Kegiatan pembelajaran

- Sisaw menerima puisi yang telah dilepaskan

- Siswa melengkapi puisi yang telah dilepaskan

- Siswa menukarkan hasil kerjanya kepada teman lain

- Guru membacakan / memperdengarkan puisi aslinya

- Kegiatan apresiasi

3. Pengamatan

Pada tahap ini pengamatan dilakukan oleh kepala sekolah sebagai obsever. Pada kegiatan pengamatan ini 
mengamati jalannya pelaksanaan proses pembelajaran dari awal hingga akhir dengan tujuan untuk mengetahui kemungkinan-kemungkinan yang terjadi selama kegiatan pembelajaran berlangsung.

4. Refleksi

Tahap ini merupakan tahap akhir setiap siklus, peneliti menyimpulkan dan mengevaluasi jalanya kegiatan yang telah dilaksanakan dengan maksud untuk mengetahui dan untuk menemukan hal-hal yang terjadi selama kegiatan berlangsung untuk mengetahui letak keberhasilan dan hambatan yang baru saja dilaksanakan sebagai bahan masukan pada perencanaan siklus berikutnya.

\section{SIKLUS II}

\section{Perencanaan}

Pada tahap peneliti menentukan langkah-langkah sebagai berikut :

a) Mempersiapkan rencana pembelajaran

b) Mempersiapkan teks puisi yang telah dilepaskan

c) Guru bersama siswa membahas proses pembelajaran yang akan dilaksanakan meliputi :

- Siswa menerima puisi yang telah dilepaskan

- Siswa melengkapi puisi yang telah dilepaskan

- Siswa menukarkan hasil kerjanya kepada teman lain

- Guru membacakan / memperdengarkan puisi aslinya

- Kegiatan apresiasi

d) Guru membuat format pengamatan

2. Pelaksanaan

Dalam tahap pelaksanaan ini langkah-langkah yang ditempuh adalah sebagai berikut :

a) Persiapan guru meliputi :

- Menyiapkan teks puisi yang telah dilepaskan

- Menyiapkan teks puisi aslinya

- Menyiapkan format pengamatan

b) Kegiatan pembelajaran

- Siswa menerima puisi yang telah dilepaskan

- Siswa melengkapi puisi yang telah dilepaskan

- Siswa menukarkan hasil kerjanya kepada teman lain
- Guru membacakan / mendengarkan puisi aslinya

- Kegiatn apresiasi

3. Pengamatan

Pada tahap ini pengamatan dilakukan oleh kepala sekolah sebagai observer. Pada kegiatan pengamatan ini mengamati jalannya pelaksanaan proses pembelajaran dari awal hingga akhir dengan tujuan untuk mengetahui kemungkinan-kemungkinan yang terjadi selama kegiatan pembelajaran berlangsung.

4. Refleksi

Tahap ini merupakan tahap akhir setiap siklus, penelitian menyimpulkan dan mengevaluasi jalannya kegiatan yang telah dilaksanakan dengan maksud untuk mengetahui dan untuk menemukan hal-hal yang terjadi selama kegiatan berlangsung untuk mengetahui letak keberhasilan dan hambatan yang baru saja dilaksanakan sebagai bahan masukan pada perencanaan siklus berikutnya.

SIKLUS III

1. Perencanaan

Pada tahap penelitian menentukan langkah-langkah sebagai berikut :

a. Mempersiapkan rencana pembelajaran

b. Mempersiapkan teks puisi yang telah dilepaskan

c. Guru bersama siswa membahas proses pembelajaran yang akan dilaksanakan meliputi :

- Siswa menerima puisi yang telah dilepaskan

- Siswa melengkapi puisi yang telah dilepaskan

- Siswa menukarkan hasil kerjanya kepada teman lain

- Guru membacakan / memperdengarkan puisi aslinya

- Kegiatan apresiasi

d. Guru membuat format pengamatan

2. Pelaksanaan

Dalam tahap pelaksanaan ini langkah-langkah yang ditempuh adalah sebagai berikut :

a. Persiapan guru meliputi :

- Menyiapkan teks puisi yang telah dilepaskan

- Menyiapkan teks puisi aslinya

- Menyiapkan format pengamatan

b. Kegiatan pembelajaran 
- Siswa menerima puisi yang telah dilepaskan

- Siswa melengkapi puisi yang telah dilepaskan

- Siswa menukarkan hasil kerja kepada teman lain

- Guru membacakan / mendengarkan puisi aslinya

- Kegiatan apresiasi

3. Pengamatan

Pada tahap ini pengamatan dilakukan oleh kepala sekolah sebagai oserver. Pada kegiatan pengamatan ini mengamati jalannya pelaksanaan proses pembelajaran dari awal hingga akhir dengan tujuan untuk mengetahui kemungkinan-kemungkinan yang terjadi selama kegiatan pembelajaran berlangsung.

4. Refleksi

Tahap ini merupakan tahap akhir setiap siklus, penelitian menyimpulkan dan mengevaluasi jalannya kegiatan yang telah dilaksanakan dengan maksud untuk mengetahui dan untuk menemukan hal-hal yang terjadi selama kegiatan berlangsung untuk mengetahuai letak keberhasilan dan hambatan yang baru saja dilaksanakan

A. Waktu dan Lokasi Penelitian

Kegiatan penelitian ini dilaksanakan pada bulan Januari tahun 2017 Semester II di SD Negeri No.07 Sungai Tawar Kecamatan Koto XI Tarusan.

B. Subyek Penelitian

Subyek penelitian adalah sebagaian (dipilih secara random ) siswa Kelas VI SD
Negeri No.07 Sungai Tawar Kecamatan Koto

XI Tarusan yang berjumlah 10 siswa.

C. Tehnik Pengolah Data

Tehnik pengumpulan data yang digunakan dalam pengumpulan data pada penelitian ini menggunakan teknik observasi.

D. Instrumen Penelitian

Dalam penelitian ini peneliti menggunakan tingi instrumen, yaitu :

1. Instrumen puisi yang telah dilepaskan Instrumen ini digunakan sebagai alat untuk mengetahui daya imajinasi siswa dengan melengkpi kata-kata yang telah dilepaskan.

2. Instrumen lebar penilaian hasil belajar siswa

Instrumen ini digunakan untuk mengetahui nilai hasil belajar siswa selama proses pembelajaran

3. Instrumen lembar pengamatan aktivitas belajar siswa

Instrumen ini berfungsi untuk mengetahui aktivitas belajar siswa selama proses pembelajaran

4. Instrumen lembar hambatan

Instrumen ini berfungsi untuk mengetahui hambatan yang ditemui siswa selama proses pembelajaran.

Analisa data yang peneliti gunakan dalam kegitan penelitian ini adalah menghitung ketuntasan hasil belajar siswa terhadap SKM yang telah ditentukan SKM yang digunakan peneliti nilai 75 , artinya anak dikatakan tuntas belajar apabila memiliki nilai paling menghitung nilai individu adalah :

Nilai $=$ Jumlah perolehan sekor yang dicapai $\times 100$

Jumlah sekor keseluruhan

\section{HASIL PENELITIAN DAN PEMBAHASAN}

Hasil dari penelitian yang dilaksanakan terhadap 10 siswa pada Kelas VI SD Negeri No.07 Sungai Tawar Kecamatan Koto XI Tarusan dapat ditabulasikan seperi dibawah ini.

1. Pembahasan Nilai-nilai Belajar
Berdasarkan data nilai di atas, maka hasil penelitian ini dapat dijelaskan sebagai berikut :

a) Pada siklus I pembelajaran dengan menggunakan tehnik cloze (dilition ) pencapaian rata-rata kelas adalah 
75, sekaligus menggambarkan keberhasilan belajar dalam satu kelas mencapai $75 \%$. Dalam silkus I terdapat dalam siswa yang nilai hasil belajarnya dibawah SKM.

b) Pada siklus II pembelajaran dengan menggunakan tehnik cloze (dilition) pencapaian nilai rata-rata kelas adalah 80. Sekaligus dapat kita ketahui tingkat keberhasilan belajar dalam satu kelas mencapai $80 \%$. Dalam pembelajaran siklus II ini terdapat tiga siswa yang nilai hasil belajarnya dibawah SKM.

c) Pada siklus III pembelajaran dengan menggunakan tehnik cloze (dilition) pencapaian nilai-nilai kelas adalah 87 yang menggambarkan tingkat keberhasilan belajar siswa dalam

\section{KESIMPULAN DAN SARAN}

Berdasarkan data hasil penelitian penggunaan tehnik cloze (dilition) pada pembelajaran puisi dapatlah disimpulkan sebagai berikut :

1. Pembelajaran / penyajian puisi di kelas dengan menggunkan tehnik cloze dapat meningkatkan aktivitas siswa Kelas VI SD Negeri No.07 Sungai Tawar Kecamatan Koto XI Tarusan selama proses pembelajaran.

2. Penggunaan tehnik cloze dalam pembelajaran puisi dapat meningkatkan satu kelas mencapai 87\%.Dalam pembelajaran siklus III ini nilai siswa semuanya di atas SKM.

Hambatan Selama PTK Berlangsung

1. Hambatan yang terjadi

Hambatan-hambatan yang ditemui dalam dalam penelitian ini adalah : masih terdapat siswa yang kurang mengkonkritkan kata dari hasil berimajinasi karena kurang memiliki perbendaharaan kata.

2. Pemecahan hambatan

Untuk mengatasi hambatan yang dialami siswa dalam mengkonkritkan kata hasil berimajinasi adalah siswa disarankan untuk lebih banyak berlatih berimajinasi terdapat puisi, karena dengan sering berimajinasi akan terlahir kata-kata yang kongkrit.

prestasi siswa Kelas VI SD Negeri No.07 Sungai Tawar Kecamatan Koto XI Tarusan.

Sehubungan dengan kesimpulan di atas, saran yang dapat penulis kemukakan adalah bagi para pengajar / guru dalam pembelajaran puisi hendaknya menggunakan tehnik cloze (dilition)

Atau kelesapan karena tehnik ini dapat mendorong siswa dalam proses berimajinasi terhadap puisi juga dapat meningkatkan kreativitas berfikir. 


\section{DAFTAR PUSTAKA}

Aminudin. 1984. Pengantar Mendalam Unsurunsur Dalam Karya Sastra. Malang : FPBS IKIP Malang.

Arikunto, Suharsini. 2006. Penelitian Tindakan Kelas. Jakarta : Bumi Aksara.

Atmazaki. 2001. Ilmu Sastra Teori Terapan. Padang: Angasa Raya.

Departemen Pendidiakan Nasional. 2003 Kurikulum Berbasis Kopetensi. Jakarta : Departemen Pendidikan Nasional
Pendopo Rachmat Djoko. 2001. Pengkajian Puisi Yogyakarta : Gajah Mada University Press

Santoso, Barokah .2003 Pembelajaran Apresiasi Sastra. Surabaya : Balai Penelitian Guru

Situmorong. BP. 1974. Puisi dan Metodologi Pengajarannya. Medan : Nusa Indah

Yunarsih, Sri. 1999. Puisi Pengantar Teori Apresiasi. Tuban : FPBS IKIP PGRI Tuban 